\title{
Peroxovanadium(V) Complexes of L-Lactic Acid as Studied by NMR Spectroscopy
}

\author{
Licínia L. G. Justino, ${ }^{[a]}$ M. Luísa Ramos, ${ }^{\text {[a] }}$ M. Madalena Caldeira, ${ }^{[a]}$ and \\ Victor M. S. Gil*[a]
}

Keywords: Vanadium / Peroxo complexes / L-Lactic acid / Multinuclear NMR spectroscopy

A multinuclear $\left({ }^{1} \mathrm{H},{ }^{13} \mathrm{C},{ }^{17} \mathrm{O},{ }^{51} \mathrm{~V}\right)$ 1D and 2D NMR study of the complexation of L-lactic acid with vanadium(V) and hydrogen peroxide shows that four peroxo complexes are formed in aqueous solution in the $\mathrm{pH}$ range $1-7$. Two isomeric 2:2:1 (metal:ligand:peroxo) complexes, together with a 2:2:2 species, are found over the entire $\mathrm{pH}$ range. At $\mathrm{pH}$ values below 2 an additional 1:1:1 complex is formed. The acid was found in all cases to act as a bidentate ligand through the carboxylic and the adjacent hydroxyl groups. To the best of our knowledge, this is the first report of dinuclear peroxovanadium complexes in which one of the metal centres is an oxovanadium centre (2:2:1 species).

\section{Introduction}

Over the past few years increasing attention has been paid to the chemistry of peroxovanadium(V) complexes. This interest is mainly due to the important role of these complexes in biological systems and their application in oxidation reactions. Peroxovanadium(V) complexes have been found to have antitumour ${ }^{[1]}$ and insulin mimetic activities, ${ }^{[2,3]}$ and have been studied as functional models for the vanadium haloperoxidase enzymes. ${ }^{[4,5]}$ These enzymes catalyse the oxidation of halides by hydrogen peroxide and are thought to be involved in the biosynthesis of a large number of marine natural products, many of them with potent antifungal, antibacterial, antiviral (e.g. HIV) and antineoplastic properties. ${ }^{[6]}$ In addition, a large variety of oxidation reactions can be efficiently performed by peroxovanadium(V) complexes. These complexes have been shown to hydroxylate benzene and other aromatics, epoxidise and hydroxylate alkenes and allylic alcohols and oxidise sulfides and primary and secondary alcohols. ${ }^{[7]}$

Previously, the vanadium(V) complexes that form with several $\alpha$-hydroxycarboxylic acids were the object of a multinuclear NMR study carried out by this group. ${ }^{[8-10]}$ In view of the interest in peroxovanadium $(\mathrm{V})$ compounds and the need to know their structures in order to fully understand both their chemistry and biochemistry, we have now extended our previous work to the more complex systems involving hydrogen peroxide. This paper deals with the peroxo complexes that form when hydrogen peroxide is added to a mixture of a vanadate( $\mathrm{V})$ salt and L-lactic acid in aqueous solution. Our intention was to investigate these species with respect to their number, stoichiometries, structures and stability by NMR spectroscopy. This technique has been intensively used in the study of vanadium(V)/hydrogen peroxide systems, both in the presence and absence of other

[a] Department of Chemistry, University of Coimbra, 3000 Coimbra, Portugal ligands, ${ }^{[11-18]}$ and has proved to be successful in the structural characterisation of the species present in solution.

A previous ${ }^{51} \mathrm{~V}$ NMR study ${ }^{[17]}$ revealed that a monoperoxovanadium complex of L-lactic acid is formed at $\mathrm{pH}$ 1. This species was characterised as being octahedral with a 1:1:1 stoichiometry (metal:ligand:peroxo). No additional studies of this system using NMR or other techniques were found in the literature.

\section{Results and Discussion}

Vanadium(V) undergoes very complex hydrolysis and polymerization reactions in aqueous solution, forming a large variety of products depending on the concentration, $\mathrm{pH}$ and ionic strength. ${ }^{[19,20]}$ In the presence of hydrogen peroxide and a ligand such as an $\alpha$-hydroxycarboxylic acid, new equilibria are established and, as a consequence, additional species can be formed, namely peroxovanadates, oxo complexes and peroxo complexes. The formation of peroxo complexes will result, therefore, from competition between several equilibria.

${ }^{1} \mathrm{H},{ }^{13} \mathrm{C},{ }^{17} \mathrm{O}$ and ${ }^{51} \mathrm{~V}$ NMR spectra of $\mathrm{V}^{\mathrm{V}}$-L-lactic acid $-\mathrm{H}_{2} \mathrm{O}_{2}$ were obtained for $\mathrm{D}_{2} \mathrm{O}$ solutions of the complexing species (concentrations ranging from $0.15 \mathrm{M}$ to 2.0 M), with various molar ratios $\left(\mathrm{H}_{2} \mathrm{O}_{2}\right.$ :metal from $5: 1$ to $1: 1$ and metal:ligand from $3: 1$ to $1: 3$ ), and for different $\mathrm{pH}^{*}$ values $(1-9.5)$. Figure 1 shows a typical ${ }^{1} \mathrm{H}$ NMR spectrum of this system obtained for the $\mathrm{pH}^{*}$ range $2-7$. In this spectrum, signals due to several complexes, free ligand and degradation products (mainly acetaldehyde and acetic acid) are observed. The observation of distinct signals for both bound and free ligand is a consequence of slow ligand exchange on the NMR time scale.

Figure 1 also illustrates, through the presence of several L-lactic acid oxo complexes, ${ }^{[8,10]}$ the various competing equilibria in which the ligand is involved. 


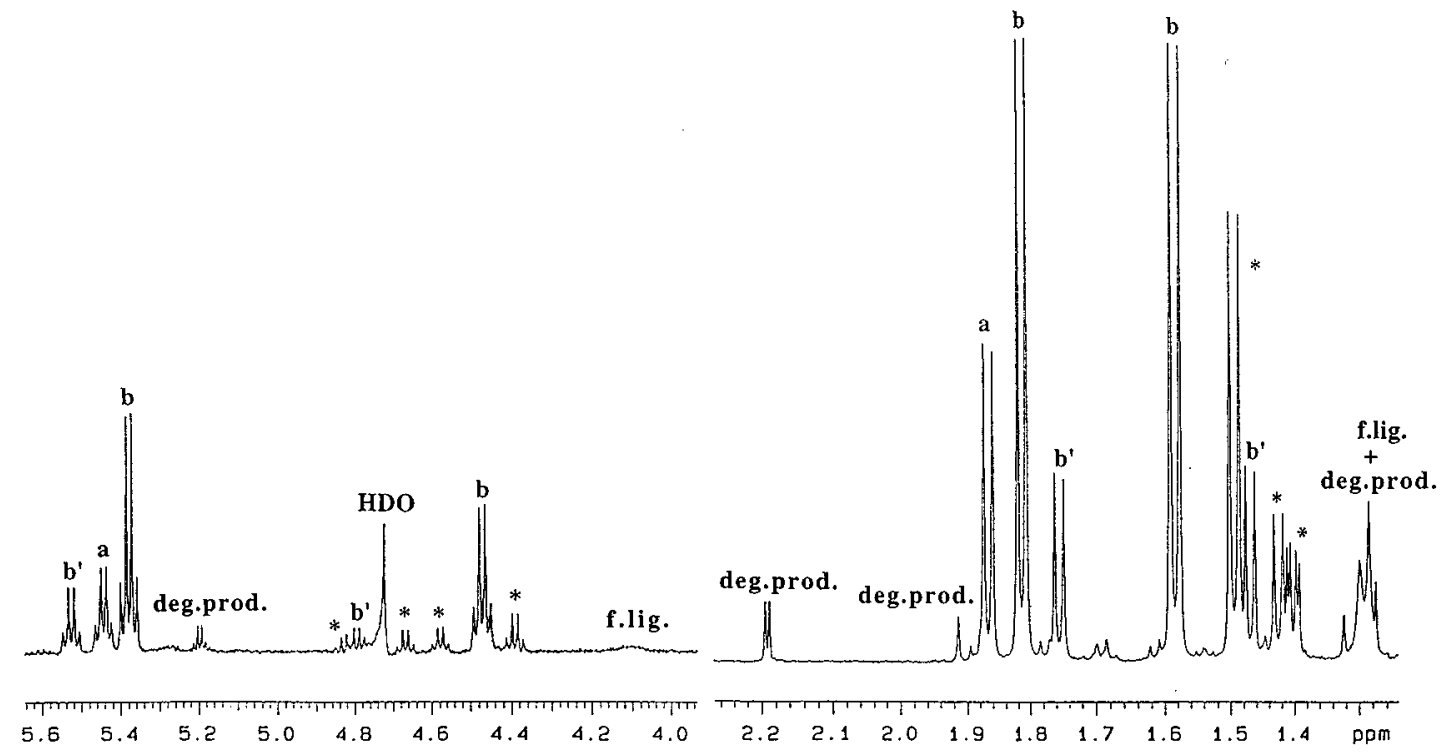

Figure 1. ${ }^{1} \mathrm{H}$ NMR spectrum (499.824 MHz) of a $0.05 \mathrm{~m}: 0.05 \mathrm{~m}: 0.05 \mathrm{~m}$ solution in $\mathrm{D}_{2} \mathrm{O}$ of $\mathrm{V}^{\mathrm{V}}-\mathrm{L}-$ lactic acid $-\mathrm{H}_{2} \mathrm{O}_{2}, \mathrm{pH}^{*}=4.0$, temp. $298 \mathrm{~K}$, approximately 3 hours after preparing the solution, $\left({ }^{*}\right)$ : oxo complexes.

Three peroxo complexes, $\mathbf{a}, \mathbf{b}$ and $\mathbf{b}^{\prime}$, are formed in the $\mathrm{pH}^{*}$ region between 2 and 7 . Their concentrations relative to the other species present in solution are at a maximum in the $\mathrm{pH}^{*}$ range $2-5 .{ }^{51} \mathrm{~V}$ NMR results show that at higher $\mathrm{pH}^{*}$ values the metal is essentially involved in the formation of peroxovanadates. At $\mathrm{pH}^{*}$ values below 2, besides a, b and $\mathbf{b}^{\prime}$, an additional complex is formed: species $\mathbf{c}$.

\section{Dinuclear Complexes}

The ${ }^{1} \mathrm{H}$ NMR spectra of complexes $\mathbf{b}$ and $\mathbf{b}^{\prime}$ show the occurrence of two different sets $\left(\mathrm{A}_{3} \mathrm{X}\right.$ spectra) of ligand signals for each complex. Attributing two sets of signals to one complex is based on the observation that the two doublets due to the methyl protons have equal intensities, irrespective of concentration and $\mathrm{pH}^{*}$ conditions. These observations suggest that both complexes $\mathbf{b}$ and $\mathbf{b}^{\prime}$ have two ligand molecules in different magnetic environments. Complex a, on the other hand, shows only one set of signals for the ligand, suggesting either the existence of only one ligand molecule in the complex or that all the ligand molecules present are magnetically equivalent. Similarly, the ${ }^{13} \mathrm{C}$ NMR spectra show the occurrence of two sets of ligand signals for complexes $\mathbf{b}$ and $\mathbf{b}^{\prime}$ and only one set for complex $\mathbf{a}$.

Table 1 shows the ${ }^{1} \mathrm{H}$ and ${ }^{13} \mathrm{C}$ NMR parameters at $\mathrm{pH}^{*}$ 4 for complexes $\mathbf{a}, \mathbf{b}$ and $\mathbf{b}^{\prime}$. HETCOR and homonuclear decoupling experiments were performed in order to assign the proton and carbon shifts of complexes $\mathbf{b}$ and $\mathbf{b}^{\prime}$.

The ${ }^{1} \mathrm{H}$ and ${ }^{13} \mathrm{C}$ chemical shifts observed for the ligand on complexation indicate which groups are bound to the metal. The high frequency shifts observed for the carboxylic carbon nucleus and the adjacent carbinol carbon and proton nuclei in complexes $\mathbf{a}, \mathbf{b}$ and $\mathbf{b}^{\prime}$ are a clear indication that those groups are involved in complexation.

An analysis of Table 1 and Figure 1 shows that one of the ligand molecules in each one of the complexes $\mathbf{b}$ and $\mathbf{b}^{\prime}$ undergoes significantly smaller ${ }^{1} \mathrm{H}$ shifts on complexation
$(0.15-0.68 \mathrm{ppm})$ than the other $(0.44-1.41 \mathrm{ppm})$. In fact, while one set of signals for each complex is found near to those of the oxo complexes, the other is found at higher frequencies.

The metal to ligand molar ratio has no significant effect on the relative concentrations of the three peroxo complexes $\mathbf{a}, \mathbf{b}$ and $\mathbf{b}^{\prime}$, which indicates that these complexes have similar metal:ligand stoichiometries. Simple calculations involving metal and ligand $\left(\mathrm{CH}_{3}\right.$ protons) signal intensities lead to the conclusion that the three peroxo complexes are n:n (metal:ligand) species.

The formation of peroxovanadium(V) complexes of L-lactic acid strongly depends on the hydrogen peroxide:metal molar ratio. Those species are present only if this ratio is equal to or smaller than 2. If greater than 2 equivalents peroxide to metal is used, peroxovanadates are the main species in solution. When equal molar amounts of hydrogen peroxide and vana$\operatorname{dium}(\mathrm{V})$ are used, the peroxo complexes are the major species present immediately after preparation of the solution. If the ratio is 2 , the major species initially formed is the diperoxovanadate $\left[\mathrm{VO}(\mathrm{OO})_{2}\left(\mathrm{H}_{2} \mathrm{O}\right)_{n}\right]^{-}$. Over time, as the peroxide concentration decreases due to disproportionation catalysed by vana$\operatorname{dium}(\mathrm{V}),{ }^{[13]}$ the concentration of the peroxovanadates decreases and the concentration of L-lactic acid peroxo complexes increases. These results suggest that no more than one peroxide ion is involved for each metal centre. This conclusion is supported by ${ }^{51} \mathrm{~V}$ NMR results. ${ }^{51} \mathrm{~V}$ chemical shifts in vanadium complexes are known to be sensitive to the coordination number and to the nature of the ligands. For $\alpha$-hydroxycarboxylic acids, such as L-lactic acid, ${ }^{51} \mathrm{~V}$ signals at approximately $\delta=-595$ have been attributed to monoperoxo species which have a seven-coordinate $\mathrm{VO}^{3+}$ metal centre. ${ }^{[21]}$ Figure 2 shows a ${ }^{51} \mathrm{~V}$ NMR spectrum where three signals ascribed to complexes $\mathbf{a}, \mathbf{b}$ and $\mathbf{b}^{\prime}$ are observed at approximately $\delta=$ -595 , indicating that these complexes have monoperoxovana$\operatorname{dium}(\mathrm{V})$ centres. However, two additional signals attributed to 
Table 1. ${ }^{1} \mathrm{H}$ and ${ }^{13} \mathrm{C}$ NMR parameters for $\mathrm{V}^{\mathrm{V}}+$ L-lactic acid $+\mathrm{H}_{2} \mathrm{O}_{2}$ at $\mathrm{pH}^{*}=4.0\left({ }^{1} \mathrm{H}\right)$ and $\mathrm{pH}^{*}=4.2\left({ }^{13} \mathrm{C}\right)(298 \mathrm{~K})$

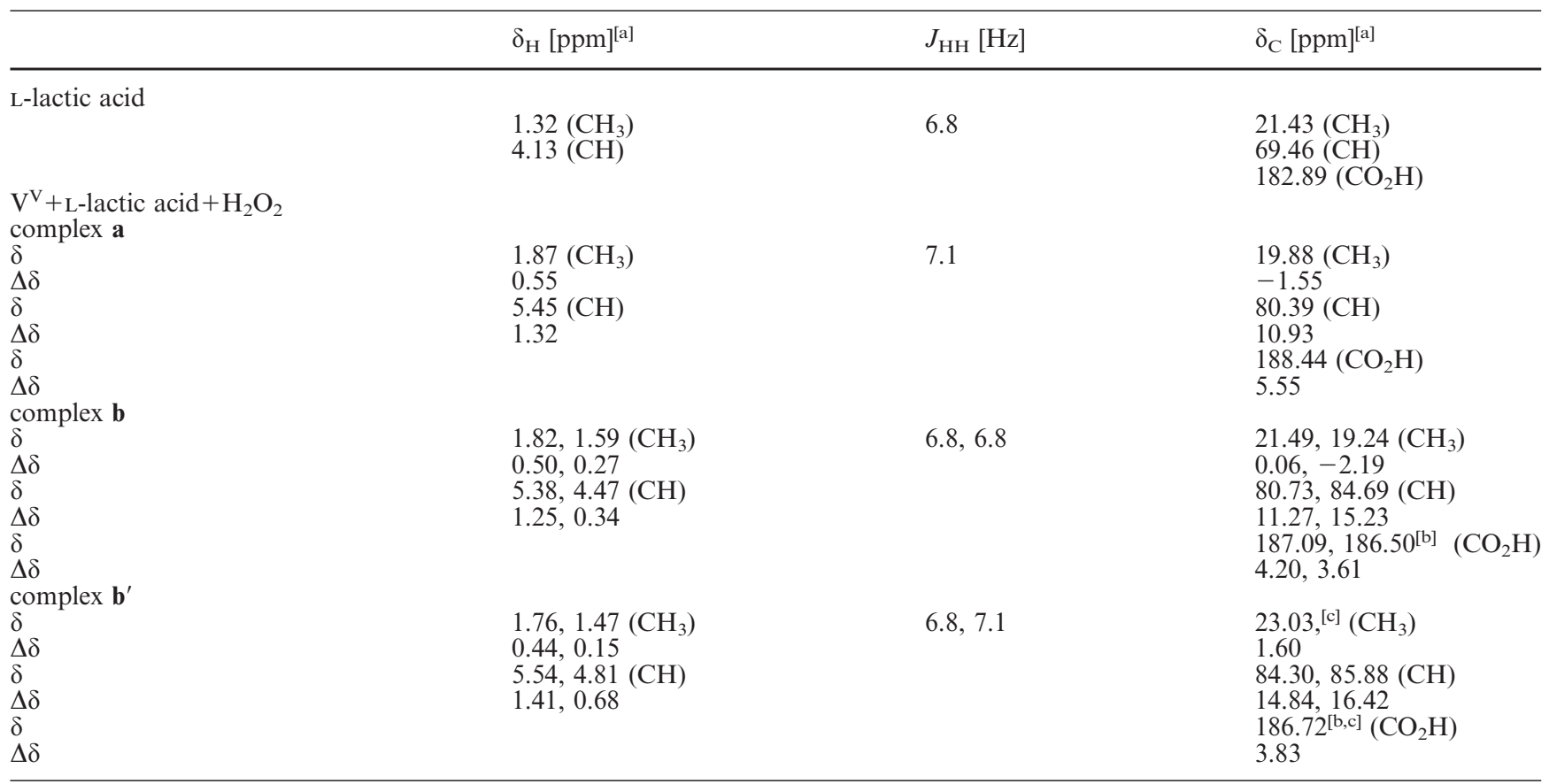

[a] $\delta$ Values relative to TMS, using tert-butyl alcohol $\left(\delta_{\mathrm{H}} 1.2, \delta_{\mathrm{C}} 31.2\right)$ as internal reference. $-[\mathrm{b}]$ The oblique line refers to the possibility of a reverse assignment. - ${ }^{[\mathrm{c}]}$ Not observed due to its superposition with more intense signals.

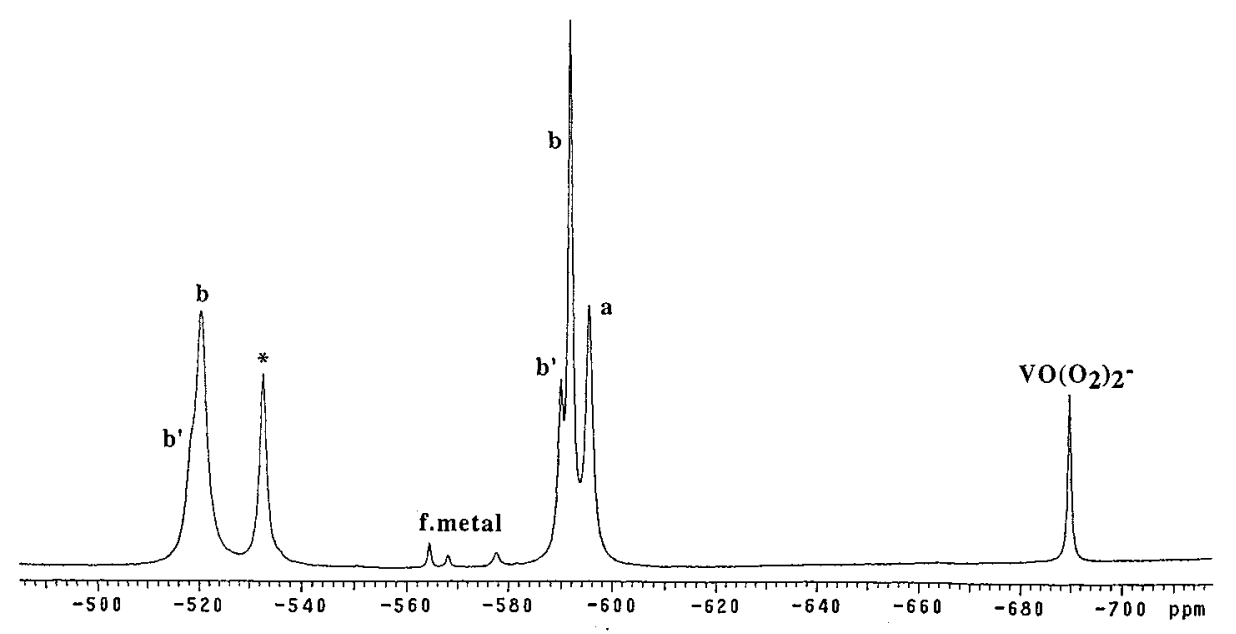

Figure 2. ${ }^{51} \mathrm{~V}$ NMR spectrum (131.404 MHz) of a $0.05 \mathrm{M}: 0.05 \mathrm{~m}: 0.05 \mathrm{~m}$ aqueous $\left(30 \% \mathrm{D}_{2} \mathrm{O}\right)$ solution of $\mathrm{V}^{\mathrm{V}}-\mathrm{L}-\mathrm{lactic}$ acid $-\mathrm{H}_{2} \mathrm{O}_{2}, \mathrm{pH}^{*}=$ 4.5 , temp. $298 \mathrm{~K}$, approximately 24 hours after preparing the solution, $(*)$ : oxo complex.

the complexes $\mathbf{b}$ and $\mathbf{b}^{\prime}$ are observed at approximately $\delta=$ -520 (Figure 2 and Table 2).

The assignment of the two signals at $\delta=-518.6$ and -520.4 was made possible by a time-dependent ${ }^{51} \mathrm{~V}$ NMR study, which shows that the disappearance of the signal due to complex $\mathbf{a}$ is followed by the appearance of two sets of signals, each with two peaks of equal intensity. By combining these data with the information provided by ${ }^{1} \mathrm{H}$ NMR spectra, the two ${ }^{51} \mathrm{~V}$ signals of greater intensity can be attributed to complex $\mathbf{b}$ and the two weaker signals to complex $\mathbf{b}^{\prime}$. We note that in the meantime part of the hydrogen peroxide has
Table 2. ${ }^{51} \mathrm{~V}$ NMR chemical shifts for $\mathrm{V}^{\mathrm{V}}+\mathrm{L}$-lactic acid $+\mathrm{H}_{2} \mathrm{O}_{2}$ at $298 \mathrm{~K}$

\begin{tabular}{lr}
\hline & $\delta_{\mathrm{V}}[\mathrm{ppm}]^{[\mathrm{a}]}$ \\
\hline $\mathrm{V}^{\mathrm{V}}+\mathrm{L}-1$ actic acid $+\mathrm{H}_{2} \mathrm{O}_{2}$ & \\
complex a $\left(\mathrm{pH}^{*} 4.0\right)$ & -595.9 \\
complex b $\left(\mathrm{pH}^{*} 4.0\right)$ & $-520.4,-592.2$ \\
complex b $\left(\mathrm{pH}^{*} 4.0\right)$ & $-518.6,-590.6$ \\
complex c $\left(\mathrm{pH}^{*} 1.1\right)$ & -546.0 \\
\hline
\end{tabular}

[a] $\delta$ Values relative to $\mathrm{VOCl}_{3}$ as external reference. 
disproportionated and signals due to free metal can consequently be detected. ${ }^{51} \mathrm{~V}$ chemical shifts at $-520 \mathrm{ppm}$ are not, however, expected for peroxo complexes, but for fivecoordinate oxovanadium(V) complexes. ${ }^{[21]}$

These results, together with the previously mentioned observations concerning the ${ }^{1} \mathrm{H}$ NMR data, suggest that $\mathbf{b}$ and $\mathbf{b}^{\prime}$ are probably isomers of stoichiometry 2:2:1 (metal:ligand:peroxo). Several hypotheses could be advanced for the structure of these complexes, depending on the groups involved in $\mathrm{V}-\mathrm{O}-\mathrm{V}$ bridges and on the possible arrangements of the oxo and peroxo groups. We choose to propose an equatorial position (relative to the axial $\mathrm{V}=\mathrm{O}$ ) for the peroxo group in a bipyramidal pentagonal geometry on the basis of the solid state structures found by X-ray diffraction for most peroxovanadium complexes. ${ }^{[7]}$ In addition, $\mathrm{OH}$ bridging is expected to be preferred to $\mathrm{CO}_{2} \mathrm{H}$ bridging, as found for numerous peroxovanadium complexes. ${ }^{[1,22,23]}$ Ac-

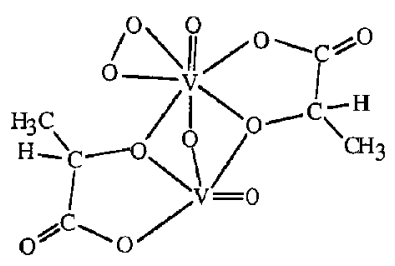

1

Scheme 1

cordingly, structure 1 (Scheme 1) can be proposed. The occurrence of two complexes can be explained by considering apical or equatorial positions for the $\mathrm{V}=\mathrm{O}$ group in the oxovanadium centre.

The two ligands and the two vanadium centres in $\mathbf{1}$ are clearly magnetically nonequivalent, one ligand spectrum showing a smaller shift on complexation and two ${ }^{51} \mathrm{~V}$ signals arising, characteristic of oxovanadium $(\mathrm{V})$ and peroxovanadium $(\mathrm{V})$ centres. This kind of dinuclear peroxovanadium complex, in which one of the metal centres is an oxovanadium centre, has not been previously reported.

Regarding complex a, its ${ }^{51} \mathrm{~V}$ chemical shift indicates a monoperoxo seven-coordinate metal centre, ${ }^{[2]}$ similar to the peroxovanadium centres of complexes $\mathbf{b}$ and $\mathbf{b}^{\prime}$. Since a 1:1:1 species would require two water molecules bound to the metal, a 2:2:2 species, which does not have this requirement, is expected to be favoured. Based on these considerations, and on the fact that the ${ }^{1} \mathrm{H}$ and ${ }^{13} \mathrm{C}$ NMR results require that the two ligand molecules are magnetically equivalent, we propose structure 2 (Scheme 2) for complex a. A similar structure has been found by $\mathrm{X}$-ray diffraction for the complex $\mathrm{K}_{2}\left[\left\{\mathrm{VO}\left(\mathrm{O}_{2}\right)\left(\mathrm{L}-\operatorname{tart} \mathrm{H}_{2}\right)\right\}_{2}\left(\mu-\mathrm{H}_{2} \mathrm{O}\right)\right] \cdot 5 \mathrm{H}_{2} \mathrm{O} \cdot{ }^{[23]}$ Additional support for this proposal is provided by the kinetic behaviour observed for the three peroxo complexes. Over time, complex a, which has two peroxovanadium centres, will convert into complexes $\mathbf{b}$ and $\mathbf{b}^{\prime}$ by losing one of the peroxo groups. This was confirmed by some experiments which showed that the addition of hydrogen peroxide to $\mathbf{b}$ and $\mathbf{b}^{\prime}$ lead to the formation of $\mathbf{a}$.

Some support for the proposed structures comes from the (natural abundance) ${ }^{17} \mathrm{O}$ NMR spectra. Although no

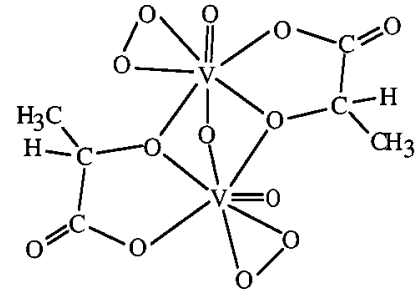

2

Scheme 2

signals due to $\mathrm{V}-\mathrm{O}-\mathrm{V}$ bridges and the peroxo groups could be detected, resonances due to terminal $\mathrm{V}=\mathrm{O}$ atoms are consistent with the presence of two equivalent $\mathrm{V}=\mathrm{O}$ groups in complex a and two nonequivalent $\mathrm{V}=\mathrm{O}$ groups in complex $\mathbf{b}$ (complex $\mathbf{b}^{\prime}$ is too weak to be detected by ${ }^{17} \mathrm{O}$ NMR). Thus, two signals at $\delta=1179.0$ and $\delta=1188.8$ are found for complexes a and $\mathbf{b}$, respectively, in accordance with reported values for other peroxovanadium(V) complexes. ${ }^{[24]}$ In addition, a signal at $\delta=1054.5$ is detected for complex $\mathbf{b}$, which is in the region of $\mathrm{V}=\mathrm{O}$ oxygen signals due to oxovanadium complexes with L-lactic acid $(\delta=$ 1094.9 and 1067.8).

\section{Mononuclear Complexes}

The ${ }^{51} \mathrm{~V}$ NMR spectra recorded for solutions at $\mathrm{pH}^{*} 1$ having a hydrogen peroxide:metal molar ratio equal to or smaller than 2 and metal:ligand molar ratios from 0.5 to 2 show, besides the signals of the complexes $\mathbf{a}, \mathbf{b}, \mathbf{b}^{\prime}$ and $\left[\mathrm{VO}(\mathrm{OO})_{2}\left(\mathrm{H}_{2} \mathrm{O}\right)_{n}\right]^{-}(\delta=-690.3),{ }^{[12]}$ the signal of the monoperoxo cation $\left[\mathrm{VO}(\mathrm{OO})\left(\mathrm{H}_{2} \mathrm{O}\right)_{n}\right]^{+}(\delta=-536.3),{ }^{[11,12]}$ the peaks of the two major oxovanadium complexes of L-lactic acid $(\delta=-533.3 \text { and }-542.4)^{[8,10]}$ and a signal at $\delta=$ -546.0 . The latter is attributed to a new peroxovanadium(V) complex, species $\mathbf{c}$. This species is especially favoured if the hydrogen peroxide:metal molar ratio is equal to 1 . Over time, complex $\mathbf{c}$ disappears and the oxo complexes become the dominant species.

The ${ }^{1} \mathrm{H}$ NMR spectra of the same solutions show the peaks of complexes $\mathbf{a}, \mathbf{b}, \mathbf{b}^{\prime}$, those of one of the oxo complexes and a broad dominant signal at $\delta=1.39$ which coincides with the chemical shift of the $\mathrm{CH}_{3}$ protons of the other oxo complex. However, the corresponding $\mathrm{CH}$ signal is not observed. Over time, as complex c disappears, the $\mathrm{CH}$ signal of the oxo complex becomes visible and the peak at $\delta=1.39$ becomes a well defined doublet. These results suggest that the ligand is involved in a rapid (on the NMR time scale) exchange process between species $\mathbf{c}$ and one of the oxo complexes, leading to extreme broadening of the $\mathrm{CH}$ signals (they are not observed) and to the coalescence of the $\mathrm{CH}_{3}$ resonances into a broad signal. Because of rapid degradation of complex $\mathbf{c}$, it was not possible to obtain any ${ }^{13} \mathrm{C}$ NMR spectra of this species.

Based on the ${ }^{51} \mathrm{~V}$ chemical shift, which is typical of sixcoordinated species, ${ }^{[21]}$ we can propose $\mathbf{c}$ as being a six-coordinated complex having a 1:1:1 (metal:ligand:peroxo) stoichiometry. A 1:2:1 species would mean the metal is 
seven coordinate. The ligand will probably be bound in the equatorial plane, as found by $\mathrm{X}$-ray diffraction for the complex $\mathrm{VO}(\mathrm{OO})\left(\mathrm{C}_{5} \mathrm{H}_{4} \mathrm{NCOO}\right)\left(\mathrm{H}_{2} \mathrm{O}\right)_{2} \cdot{ }^{[25]}$ The remaining position in the coordination shell would be occupied by one water molecule. A possible structure for $\mathbf{c}$ is $\mathbf{3}$ (Scheme 3), which has been previously proposed by other authors. ${ }^{[17]}$

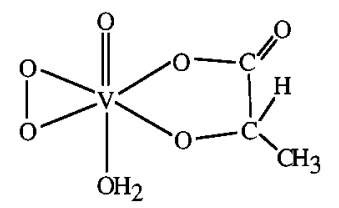

3

Scheme 3

\section{Conclusion}

In the presence of hydrogen peroxide and L-lactic acid, vanadium(V) forms several complexes in aqueous solution, L-lactic acid peroxovanadium complexes among them. The aim of the present study was to obtain information on the latter by using multinuclear NMR spectroscopy.

Four peroxo complexes were found to form under the conditions of this study. At low-intermediate $\mathrm{pH}(2-7)$, three dimeric complexes are formed, two of them (2:2:1 species) being the result of partial degradation (loss of one peroxide unit) of a bis(peroxide) complex (2:2:2 species). Dimeric 2:2:2 peroxovanadium complexes have been characterised by X-ray diffraction for other $\alpha$-hydroxycarboxylic acids, such as citric, ${ }^{[1]}$ DL-malic ${ }^{[22]}$ and L-tartaric acids. ${ }^{[23]}$ At very low pH (below 2) a 1:1:1 species is detected in addition to these complexes. This latter result is consistent with the tendency of vanadium ions to undergo depolymerization in very acidic media.

\section{Experimental Section}

Analytical grade ammonium vanadate $(\mathrm{V})$ and commercially available L-lactic acid and hydrogen peroxide (35\%) were used. Vanadate, lactic acid and hydrogen peroxide stock solutions were prepared. The hydrogen peroxide stock solution was prepared immediately prior to use. The concentrations of the vanadate and acid solutions were established by weight. Prior to use, the $\mathrm{D}_{2} \mathrm{O}$ lactic acid solution was heated in boiling water for 2 hours to accomplish depolymerization. The samples were prepared by adding the appropriate amounts of the stock vanadate, lactic acid and hydrogen peroxide solutions. The $\mathrm{pH}$ was adjusted (cautiously, to reduce the possibility of drastic local disturbances of equilibria that may be slow to disappear) by addition of solutions of $\mathrm{DCl}$ and $\mathrm{NaOD}$; the $\mathrm{pH}^{*}$ values quoted are the direct $\mathrm{pH}$-meter readings (room temperature) after standardization with aqueous $\left(\mathrm{H}_{2} \mathrm{O}\right)$ buffers. The ${ }^{1} \mathrm{H}$ and ${ }^{13} \mathrm{C}$ NMR spectra were obtained on a Varian UNITY-500 NMR spectrometer (at 499.824 and $125.692 \mathrm{MHz}$, respectively). The residual water signal was reduced by using the Presat sequence. The ${ }^{13} \mathrm{C}$ spectra were recorded using proton-decoupling techniques with suppression of the nuclear Overhauser effect. The methyl sig- nal of tert-butyl alcohol was used as internal reference for ${ }^{1} \mathrm{H}(\delta=$ 1.2) and ${ }^{13} \mathrm{C}(\delta=31.2)$ relative to TMS. The ${ }^{51} \mathrm{~V}$ and ${ }^{17} \mathrm{O}$ spectra were obtained on the same spectrometer (131.404 and $67.792 \mathrm{MHz}$, respectively) using $\operatorname{VOCl}_{3}(\delta=0)$ and $\mathrm{D}_{2} \mathrm{O}(\delta=0)$ as external references for ${ }^{51} \mathrm{~V}$ and ${ }^{17} \mathrm{O}$ shifts, respectively. Typically, spectral widths of $30000 \mathrm{~Hz}$, acquisition times of $1 \mathrm{~s}$, pulse delays of $10 \mathrm{~s}$ and 5000 pulses were used when recording ${ }^{13} \mathrm{C}$ spectra. For ${ }^{51} \mathrm{~V}$ and ${ }^{17} \mathrm{O}$ spectra, the corresponding parameters were 80000 and $100000 \mathrm{~Hz}, 0.04$ and $0.02 \mathrm{~s}, 0.01$ and $0 \mathrm{~s}$, about 16000 and $4 \times 10^{6}$ pulses, respectively. The $2 \mathrm{D}$ NMR spectra, HETCOR, ${ }^{[26]}$ were also recorded on the Varian UNITY-500 NMR spectrometer.

\section{Acknowledgments}

This work has been supported by "Fundação para a Ciência e a Tecnologia", of the Portuguese Ministry of Science and Technology (Project PRAXIS QUI-63/96). The authors are also indebted to the referees for some suggestions.

[1] C. Djordjevic, M. Lee, E. Sinn, Inorg. Chem. 1989, 28, 719-723 and references therein.

[2] A. Shaver, J. B. Ng, D. A. Hall, B. S. Lum, B. I. Posner, Inorg. Chem. 1993, 32, 3109-3113.

${ }^{[3]}$ B. I. Posner, R. Faure, J. W. Burgess, A. P. Bevan, D. Lachance, G. Zhang-Sun, I. G. Fantus, J. B. Ng, D. A. Hall, B. S. Lum, A. Shaver, J. Biol. Chem. 1994, 269, 4596-4604.

${ }^{[4]}$ G. J. Colpas, B. J. Hamstra, J. W. Kampf, V. L. Pecoraro, J. Am. Chem. Soc. 1994, 116, 3627-3628.

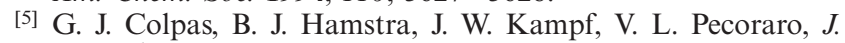
Am. Chem. Soc. 1996, 118, 3469-3478.

[6] A. Butler, J. V. Walker, Chem. Rev. 1993, 93, 1937-1944.

[7] A. Butler, M. J. Clague, G. E. Meister, Chem. Rev. 1994, 94, 625-638.

${ }^{[8]}$ M. M. Caldeira, M. L. Ramos, N. C. Oliveira, V. M. S. Gil, Can. J. Chem. 1987, 65, 2434-2440.

[9] M. M. Caldeira, M. L. Ramos, A. M. Cavaleiro, V. M. S. Gil, J. Mol. Struct. 1988, 174, 461-466.

${ }^{[10]}$ V. M. S. Gil, Pure and Appl. Chem. 1989, 61, 841-848.

${ }^{[11]}$ A. T. Harrison, O. W. Howarth, J. Chem. Soc., Dalton Trans. 1985, 1173- 1177.

${ }^{[12]}$ N. J. Campbell, A. C. Dengel, W. P. Griffith, Polyhedron 1989, 8, 1379-1386

[13] J. S. Jaswal, A. S. Tracey, Inorg. Chem. 1991, 30, 3718-3722.

${ }^{[14]}$ A. S. Tracey, J. S. Jaswal, J. Am. Chem. Soc. 1992, 114, $3835-3840$.

[15] J. S. Jaswal, A. S. Tracey, J. Am. Chem. Soc. 1993, 115, $5600-5607$.

[16] V. Conte, F. Di Furia, S. Moro, J. Mol. Catal. 1994, 94, $323-333$.

[17] V. Conte, F. Di Furia, S. Moro, J. Mol. Catal. A 1995, 104, $159-169$.

${ }^{[18]}$ M. S. Reynolds, A. Butler, Inorg. Chem. 1996, 35, 2378-2383.

${ }^{[19]}$ C. F. Baes, R. E. Mesmer, The Hydrolysis of Cations, Wiley; New York, 1976, pp. 201-210 and refs therein.

${ }^{[20]}$ E. Heath, O. W. Howarth, J. Chem. Soc., Dalton Trans. 1981, $1105-1110$.

${ }^{[21]}$ D. Rehder, C. Weidemann, A. Duch, W. Priebsch, Inorg. Chem. 1988, 27, 584-587.

[22] C. Djordjevic, M. Lee-Renslo, E. Sinn, Inorg. Chim. Acta 1995, 233, 97-102.

${ }^{[23]}$ P. Schwendt, P. Svancárek, L. Kuchta, J. Marek, Polyhedron 1998, 17, 2161- 2166.

${ }^{[24]}$ M. Postel, C. Brevard, H. Arzoumanian, J. G. Riess, J. Am. Chem. Soc. 1983, 105, 4922-4926.

${ }^{[25]}$ H. Mimoun, L. Saussine, E. Daire, M. Postel, J. Fischer, R. Weiss, J. Am. Chem. Soc. 1983, 105, 3101-3110.

${ }^{[26]}$ A. D. Bax, G. A. Morris, J. Magn. Reson. 1981, 42, 51-59; A. D. Bax, J. Magn. Reson. 1983, 53, 517-520; J. A. Wilde, P. H. Bolton, J. Magn. Reson. 1984, 59, 343-346. 